\title{
Empty Nest, Cohort, and Employment in the Well-Being of Midlife Women ${ }^{1}$
}

\author{
Pamela K. Adelmann ${ }^{2}$ and Toni C. Antonucci \\ University of Michigan
}

Susan E. Crohan

University of Wisconsin

Lerita M. Coleman

University of Tennessee

Whether the empty-nest experience has positive or negative consequences for women's well-being at midlife may depend on their historical cohort membership and employment status. In this study, it was posited that the empty nest was likely to be a negative experience among the particular cohort of women (Cohort II) who reached adulthood during the period of strong societal emphasis on women's maternal role known as the feminine mystique, would be experienced positively among the earlier cohort (Cohort I) who as young adults were encouraged to enter the labor force during World War II. Analyses of covariance tested the relationships among empty-nest status, cohort membership, and employment status, and three measures of psychological well-being, adjusted for age, education, and marital status. The results of this study show that cohort and employment each have important independent associations with women's well-being at midlife, but that the experience of the empty nest depends on these two factors, especially cohort experiences.

Enormous changes have taken place in the roles of women in the past century. Attitudinal norms about paid employment have reversed several times, women's employment-related legal rights have advanced, stalled, and advanced once again, and economic pressures have alternatively pushed wom-

\footnotetext{
'The authors wish to thank Joseph Veroff, Elizabeth Douvan, and Richard Kulka for the use of the data from The Study of Modern Living, and Joseph Veroff for comments on an earlier version of this paper.

${ }^{2}$ To whom correspondence should be addressed at Department of Psychology, University of Michigan, 580 Union Drive, Ann Arbor, Michigan 48109-1346.
} 
en into the labor force and then ushered them out again (Deckard, 1975; Fox \& Hesse-Biber, 1984). Similarly, the societal importance attached to the maternal role has fluctuated through different historical periods (Chafe, 1972).

Women's well-being at midlife is thought to be largely tied to these social roles. For example, the empty-nest hypothesis centers on the importance of the maternal role to women's well-being. According to proponents of this hypothesis, the departure of the last child from home at midlife may result in depression, identity crisis, and deteriorating physical and psychological well-being (Bart, 1971; Phillips, 1957). The evidence for such an empty-nest syndrome, however, is mixed. Although occasionally revealed in clinical samples (Bart, 1971; Curlee, 1969), in other studies women in the empty-nest stage were found to have unchanging or even elevated well-being compared to women in previous stages (Axelson, 1960; Campbell, 1975; Deutscher, 1964; Lowenthal \& Chiriboga, 1972; Rollins \& Feldman, 1970). Borland (1982) concluded from her review of this literature that "the majority of the studies have found little support for the widespread existence of the emptynest syndrome" (p. 119).

Whether the empty nest is experienced as positive or negative may depend partly on historical cohort experiences (Bernard, 1975; Borland, 1982). According to Borland, "The changing roles of women over time have not been considered as a control variable in predicting the occurrence of the empty-nest syndrome. Yet each generation of women has lived with a different ideology of what constitutes appropriate women's roles" (p. 119). Borland proposed that the empty-nest syndrome is particular to the cohort of white women born in the 1920s and 1930s, and that neither the earlier generation (born around 1900 to 1920) nor the succeeding one (born from the 1940 s to $1960 \mathrm{~s}$ ) experienced the same strong socialization of familistic norms linked to a negative empty-nest experience. Bernard (1975), on the other hand, argues that empty-nest syndrome is primarily a phenomenon of the cohort of women born around 1900, and that later cohorts were more likely to anticipate and plan for a positive empty-nest period.

A second factor that may moderate the experience of the empty-nest period is whether a woman engages in paid employment. Some developmental perspectives emphasize the importance of work roles in women's wellbeing at midlife. The "crossover hypothesis" contends that women who focus on their nurturant needs early in adulthood through active involvement in motherhood by midlife may be motivated to satisfy their as yet unmet achievement needs (Guttman, 1975; Neugarten, 1968; Rossi, 1980), often through paid employment. The increasing evidence that women who are employed at midlife have higher mental and physical well-being than full-time homemakers (Coleman \& Antonucci, 1983; Faver, 1984; Powell, 1977; Rubin, 1979; Ver- 


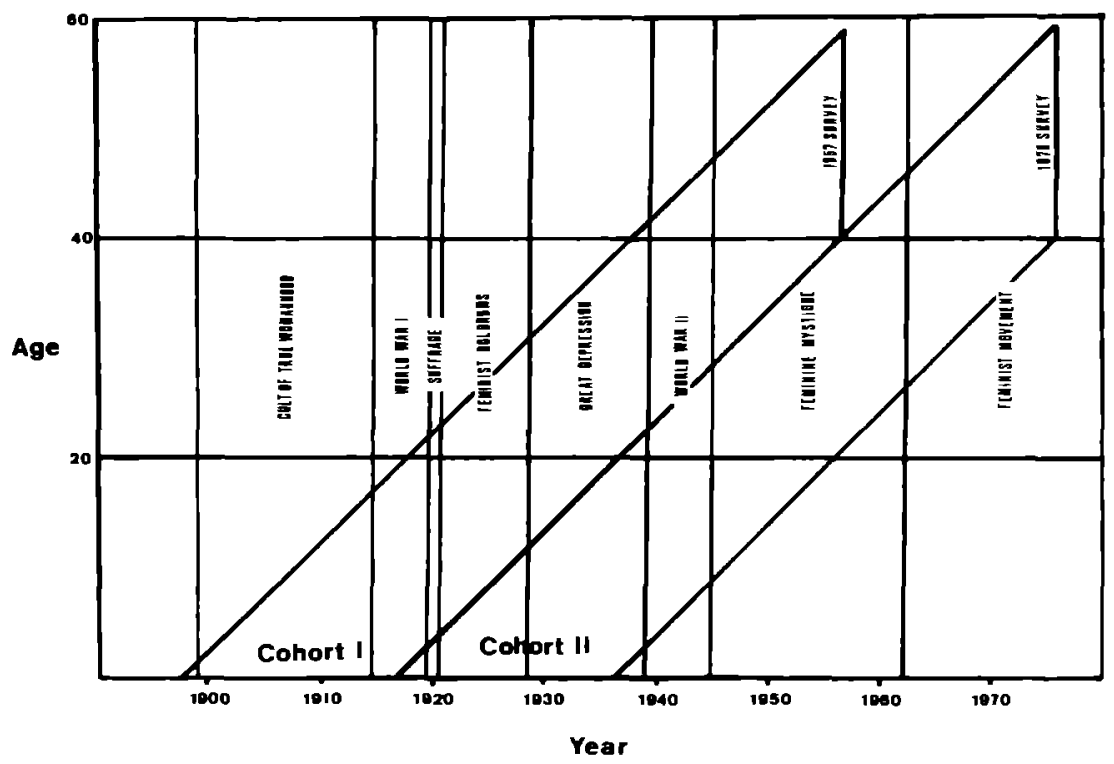

Fig. 1. Historical experiences of two cohorts of midlife women.

brugge \& Madans, 1985), particularly if combined with other roles (Baruch \& Barnett, 1986; Verbrugge \& Madans, 1985) favors this hypothesis.

Cohort membership and employment status may also interact to influence the empty-nest experience. Williams (1977), for example, proposed that midlife distress at maternal role loss is most likely among women who are homemakers and who were socialized to be overinvolved in their children (a description that matches Borland's description of the historical cohort she contended is prone to empty-nest syndrome).

In this paper we examine the relationship of empty-nest status, cohort membership, and employment status to well-being in midlife women. Using this approach we can explore the empty-nest experience as it interacts with historical cohort and employment. We begin by outlining the historical experiences of our two midlife cohorts of women, the first bom from 1898 to 1917 and the second born 1917 to 1936. The shifting emphases on women's roles in the home and employment spheres in the childhood, early adulthood, and late adulthood periods of each cohort are considered (see Fig. 1).

\section{Cohort I}

By the early 1900s, the "cult of true womanhood," a cultural norm endorsing marriage and maternity, was in full bloom (Fox \& Hesse-Biber, 1984). 
Employment was common only among young unmarried women (in 1900, half of employed women were under 25 and three-quarters were single; National Manpower Council, 1957), minority women, and recent female immigrants (Fox \& Hesse-Biber, 1984). World War I (1914-1918) did not result in substantial increases in the number of women employed, but it did temporarily result in an expansion of occupations open to women (from servant, laundress, and dressmaking occupations to clerk, typist, and operative jobs; Deckard, 1975; Fox \& Hesse-Biber, 1984). After World War I, many women were forced back into low-paying, unskilled occupations once again (Fox \& Hesse-Biber, 1984).

The biggest historical influences on the early adult lives of those Cohort I women were the occurrence of the Great Depression (1929-1944) and the U.S. entry into World War II. Normative pressures against married women working for pay continued during the Depression, yet economic difficulties forced many to seek paid employment (Scharf, 1980). The jobs available to these workers were often marginal, part time, and poorly paid (Fox \& Hesse-Biber, 1984). World War II (1939-1945) brought enormous changes for women, both in numbers employed and the range of occupations available (Fox \& Hesse-Biber, 1984). Societal norms underwent a dramatic shift (Cantril, 1951; Chafe, 1972), portraying women's participation in the labor force as a matter of patriotic duty (Chafe, 1972; Trey, 1972). The largest increases in labor force participation were among married women (Anderson, 1981); the proportions of married women employed increased from $15 \%$ in 1940 to $24 \%$ by 1950 . The proportion of all women employed jumped from around $23 \%$ in 1930 to $29 \%$ in 1940 , reaching almost $40 \%$ by the end of World War II (U.S. Department of Labor, 1979). Cohort I women were therefore quite likely to work for pay during their early adulthood and were encouraged to do so.

The end of the war coincided with the beginning of the midlife period for Cohort I. Much of this period was characterized by a norm later labeled "the feminine mystique" by Betty Friedan (1963). In order to induce women to abandon their wartime jobs to returning soliders, a strong familistic ideology for women was cultivated (Chafe, 1972; Deckard, 1975; Fox \& HesseBiber, 1984). Younger women were heavily influenced by this mystique, but midlife women such as those in Cohort I were less swayed; in one survey, 3 out of 4 women who had taken a job during the war wanted to continue working, with the proportion of employed women over age 45 who said they were interested in a permanent job reaching $80 \%$ (Chafe, 1972).

Despite the strong pressures to quit the paid labor force, there were steady increases in the proportion of women employed (after the initial sharp decline from 38 to $31 \%$ following World War II, participation climbed to $36 \%$ by 1957; U.S. Department of Labor, 1979). Oppenheimer (1970) argues that at the same time many women were pushed out of the lucrative male labor 
market, there was a steadily increasing demand in the female labor market. Since there were not enough young women to take these jobs, older women filled the demand. The largest increases of women into the labor force were among older married women - the midlife women in this cohort. The number of 35-44-year-old women in the labor force increased by $51 \%$ from 1940 to 1950 , and that of 45-54-year-olds rose $77 \%$ (Chafe, 1972), although their proportion in the population increased by only $17 \%$ during these years. By 1950, half of the employed women were over 40 years of age (National Manpower Council, 1957).

In sum, our first midlife cohort was one in which women were initially expected to work until marriage and to withdraw from the labor force thereafter. However, the combined forces of the Depression and World War II caused many women to work even after marriage. During their later adulthood, strong societal pressures to abandon the paid labor force were largely unsuccessful among this cohort, and they continued to work for pay in steadily increasing numbers. Bernard (1975) argued that this was the cohort of women especially likely to experience the empty-nest syndrome at midlife, while Borland (1982) contended the opposite. Given the young adulthood experiences of this cohort of women in work outside the home, Borland's position appears more plausible.

\section{Cohort II}

The childhood experiences of Cohort II women coincided with the early adulthood of Cohort I. The major events related to their socialization for work roles were the Depression and World War II. Their Cohort I mothers, although likely to have worked before marriage and when children were older, were liable to have done so out of financial necessity during the Depression (Scharf, 1980). The childhood norms surrounding Cohort I women were therefore likely to include some role models of employed women combined with the assumption that this work was motived primarily from necessity rather than choice.

The feminine mystique was the dominant ideology for women's roles during the early adulthood of Cohort II women. These young women adhered closely to this ideology, setting records for proportions marrying, early age at marriage, and birth rates (Borland, 1982). Given their almost immediate entry into marriage and parenthood after high school, they were unlikely to have any extensive experience in paid employment. In contrast to the older cohort of women, the proportions of employed women aged 18-24 actually dropped by $8 \%$ from 1940 to 1950 (Chafe, 1972).

Glimmerings of the feminist movement appeared as Cohort II midlife women entered the midlife period. The AFL-CIO endorsed equal pay for 
women in the late 1950s, and steady legislative advances for employed women occurred in the early 1960s: the Equal Pay Act was passed in 1963, and Title VII, which outlawed discrimination against women in hiring, was enacted in 1964 (Chafe, 1972). Ideological changes accompanied these accomplishments, heralded by Friedman's 1963 publication of The Feminine Mystique. Housework began to be defined as exploitative, demanding, and undervalued (Deckard, 1975; Glazer, 1977; Oakley, 1974). Women's participation in the labor force grew from $33 \%$ in 1950 , to $37 \%$ in 1960 , to over $40 \%$ by 1976 (U.S. Department of Labor, 1979). Yet these increases were due not to an influx of Cohort II women, but of their daughters-even the young married mothers among them (Fox \& Hesse-Biber, 1984). Cohort II women who did enter the labor force at this time were likely to find themselves limited in their employment options by lack of experience, outdated education, and competition for jobs from skilled younger women (Borland, 1982; Giele, 1982). These women were often pushed into the labor force by the "life-cycle squeeze" - the period of increased family expenses as children pass through adolescence (Gove, Grimm, Motz, \& Thompson, 1973; Oppenheimer, 1974) - or by the increasingly common experience of divorce and widowhood at midlife (Gove et al., 1973; Oppenheimer, 1974).

Cohort II women, in sum, had active role models of employed women during their early lives. But the norms surrounding their early adulthood were strong familistic ones, and most women in this cohort married and started families early. They were not likely to work for pay during early adulthood, and those who were employed later in life were faced with employment options that were incommensurate with their expectations and at odds with their socialization. Because of their heavy early investment in family roles, this cohort of women was proposed to experience the empty-nest period most negatively by Borland (1982).

\section{Summary and Hypotheses}

The empirical literature on the empty nest is contradictory, although in nonclinical samples there appears little evidence of the existence of the empty-nest syndrome. Part of the confusion in this literature may be due to the failure to consider historical cohort differences in the emphasis placed on women's family roles. Theoretical analyses have broached this possibility, but to our knowledge no empirical investigation of cohort differences in the empty-nest experience have been undertaken. Furthermore, because the employment role may be an important alternative source of self-definition and well-being at midlife but may be experienced differently in different cohorts of women, it is important to examine its relation with the empty nest in each cohort. In this paper, therefore, the psychological well-being of empty- 
nest women of different historical cohorts and employment statuses is examined.

The first hypothesized interaction is between cohort membership and empty-nest status. Our Cohort I, born around the turn of the century, experienced during young adulthood the historical forces of World War II in which the employment of women was highly encouraged (and, by default, their maternal role deemphasized). In contrast, the young women of Cohort II, born about the $1920 \mathrm{~s}$, faced strong societal emphasis on maternal involvement and active discouragement from seeking employment during the period of the feminine mystique following the war. In accord with Borland's (1982) argument, therefore, we anticipated lower well-being among emptynest than non-empty-nest women in the highly family-invested women of Cohort II and the reverse pattern in Cohort I.

Second, an interaction between empty-nest status and employment status was hypothesized. Since paid employment may cushion the effects of changes in the maternal role, we predicted higher well-being among employed empty-nest women than in those not employed, and a similar but smaller difference in well-being by employment among non-empty-nest women.

A third hypothesized interaction was of empty-nest status with both cohort and employment. We speculated that empty-nest Cohort II homemakers would have the lowest well-being of any group because they no longer have an active maternal role, for which they were strongly socialized, and do not have the employment role as a possible substitute.

Although our interest here is primarily in these three interactions, four subsidiary hypotheses can also be tested. First, because Veroff, Douvan, \& Kulka (1981) found lower well-being among Cohort II than Cohort I men and women aged 21 and over, we anticipated a parallel main effect of cohort among our midlife sample. Second, the commonly observed relationship between employment and well-being at midlife led to the hypothesis that employed midlife women in the two cohorts combined would have generally higher well-being than full-time homemakers. Because of the mixed but generally nonsignificant findings of the empty-nest syndrome, we did not hypothesize a main effect of empty-nest status. Finally, although not central to our interest in the empty-nest syndrome, we expected that if employment and cohort interact, employed women would have higher well-being than those not employed in Cohort I. Because Cohort II women had little experience with or socialization to participate in the labor force, however, in this cohort we might expect smaller differences in the same direction between employed and nonemployed women, or possibly a difference in the reverse direction.

Additionally, we note that age, education, and marital status may be confounded with other variables in our sample, and were therefore included as controls in the analyses. Based on previous analyses with these data (Gu- 
rin, Veroff, \& Feld, 1963; Veroff et al., 1981), we expected a positive relationship between education and well-being, a negative association between age and well-being, and higher well-being among married than unmarried women at midlife.

\section{METHOD}

\section{Data}

The data were taken from two cross-sectional nationwide surveys conducted by the Survey Research Center at the University of Michigan. In the 1957 survey, 2460 adults over age 21 were sampled using area-sampling probability methods (see Gurin et al., 1960). A comparable sample of 2264 adults was drawn using the same methods for the 1976 survey (Veroff et al., 1981). In both surveys, respondents were interviewed face to face on topics including role experiences, well-being, and demographic factors.

For the present study, the sample was limited to midlife mothers aged 40-59. There were 374 women in this age range in the 1957 survey and 312 midlife mothers from the 1976 data set.

\section{Variables}

Predictors. The three predictor variables included were empty-nest status, cohort membership, and employment status. The empty-nest variable was created from a family-stage variable; women who were mothers but no longer had any children at home were coded "empty nest," and those who still had at least one child under 17 at home were coded "not empty nest." Because information on time elapsed since the last child left home was not available in the data set, the duration of the empty-nest period could not be determined. Cohort membership was determined by year of survey: 1957 respondents comprised Cohort I and Cohort II contained 1976 respondents. A woman was categorized as "employed" if working outside the home for pay part time or full time, and as "homemaker" is a full-time homemaker.

Covariates. The three covariates included were age, education, and marital status. Age was coded ordinally as 40 (40-44), 45 (45-49), 50 (50-54) and 55 (55-59). Education was coded 0 (no schooling), 1 (I-6 years of school) 2 (7-8 years), 3 (9-11 years), 4 (9-11 years plus some other schooling), 5 (12 years-high school graduate), 6 (12 years plus some other schooling), 7 (some college), 8 (college degree). Marital status was coded as either married or not married (including the divorced, widowed, and never married). 
Well-Being. Three well-being measures identical in both data sets were selected as dependent variables. The indices were derived in an orthogonal factor analysis by Veroff et al. (1981) on a checklist of 20 symptoms adapted from the Stirling County (MacMillan, 1957) and Midtown (Srole et al., 1962) studies. Veroff et al. (1981) argue that the three resulting factors (psychological anxiety, immobilization, physical health) reflect three diverse but interrelated ways people express their feelings of distress; we therefore preserved the distinctions among these three indices while acknowledging their intercorrelation.

The first index, psychological anxiety, contained five items inquiring about frequency of nervousness, headache, loss of appetite, upset stomach, and trouble sleeping. Each item was coded 1 (never), 2 (not very often), 3 (pretty often), and 4 (nearly all the time). The resulting summary scores could range from 5 (low anxiety) to 20 (high anxiety), and the index had internal reliability of .71 (Cronbach alpha).

Seven items were selected to comprise the immobility index. They assessed frequency of difficulty getting up in the morning, feelings of dizziness, experience of nightmares, loss of weight when worried, trembling hands, sweating hands, and inability to get going. Frequency of difficulty getting up was coded on the same scale as above. The remaining items were coded 1 (never), 2 (hardly ever), 3 (sometimes), and 4 (many times). Scores were summed for a possible range of 8-28 (low to high immobilization). Internal reliability (Cronbach alpha) was .63.

Finally, physical health contained six items. Frequency of shortness of breath, of heart beating hard, and of ill health affecting work were scored 1 (many times), 2 (sometimes), 3 (hardly ever), and 4 (never). Questions about presence of any health problem, presence of pains and ailments, and about not being healthy enough to do things were coded 2 [yes (unhealthy)] and 4 [no (healthy)]. Summed scores could range from 8 to 24 (low to high health), with a Cronbach alpha of .77.

\section{Sample Description}

The proportions of each of the two cohorts in the empty-nest stage and in the employment and marital roles are presented in Table I. About onethird of each cohort of midlife women were in the empty-nest group. In 1957, less than $40 \%$ of the women were employed for pay, but by 1976, this proportion had surpassed the one-half mark, a significant increase. Approximately three-fourths of the women in each cohort were married.

Mean levels of the remaining variables for the two cohorts also appear in Table I. Women in 1976 were significantly older by approximately one 
Table I. Sample Descriptions for Cohorts I and II ${ }^{\alpha}$

\begin{tabular}{|c|c|c|c|}
\hline & $\begin{array}{c}\text { Cohort I } \\
\text { (born 1898-1917) }\end{array}$ & $\begin{array}{c}\text { Cohort II } \\
\text { (born 1917-1936) }\end{array}$ & \\
\hline & $\%$ Yes & $\%$ Yes & $x^{2}$ \\
\hline Empty nest & 35.8 & 33.3 & .47 \\
\hline Employed & 38.5 & 55.9 & $20.74^{d}$ \\
\hline \multirow[t]{2}{*}{ Married } & 77.5 & 74.9 & .65 \\
\hline & $\operatorname{Mean}^{b}$ & Mean $^{b}$ & $t$ \\
\hline$\overline{\text { Age }}$ & $\begin{array}{l}46.32 \\
(5.47)\end{array}$ & $\begin{array}{l}47.35 \\
(5.62)\end{array}$ & $2.42^{c}$ \\
\hline Education & $\begin{array}{r}3.92 \\
(2.15)\end{array}$ & $\begin{array}{r}4.94 \\
(1.91)\end{array}$ & $6.47^{d}$ \\
\hline Anxiety & $\begin{array}{r}9.36 \\
(2.60)\end{array}$ & $\begin{array}{r}9.75 \\
(2.27)\end{array}$ & $2.10^{c}$ \\
\hline Immobilization & $\begin{array}{l}11.76 \\
(3.59)\end{array}$ & $\begin{array}{l}12.13 \\
(3.45)\end{array}$ & I. 35 \\
\hline Health & $\begin{array}{l}21.11 \\
(3.73)\end{array}$ & $\begin{array}{l}20.95 \\
(3.38)\end{array}$ & .56 \\
\hline
\end{tabular}

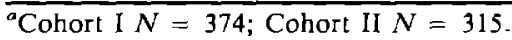

${ }^{b}$ Standard deviations are in parentheses.

${ }^{\mathrm{s}} p<.05$.

$d_{p}<.01$

year and were more highly educated. The 1957 cohort was lower in anxiety; they also had better health and lower immobilization, but these differences were not significant.

\section{Data Analysis}

Data were analyzed using analysis of covariance (ANCOVA). The model tested was a 2 (cohort membership) $\times 2$ (empty-nest status) $\times 2$ (employment status) factorial design with three dependent variables (anxiety, immobilization, and health). Age, education, and marital status were included in the model as covariates. The analysis therefore tests for differences in mean levels of anxiety, immobilization, and health by empty-nest, cohort, and employment status after adjusting for the effect of age, education, and marital status. The intercorrelations among the variables included in the analysis appear in Table II.

\section{RESULTS}

The results of the ANCOVAs are presented in Table III; cell means adjusted for age, education, and marital status appear in Table IV. 
Table II. Correlations Among Predictors, Covariates, and Dependent Variables ${ }^{0}$

\begin{tabular}{lrrrrrrrr}
\hline & $\mathrm{I}$ & 2 & 3 & 4 & 5 & 6 & 7 & 8 \\
\hline 1. Empty nest & - & & & & & & & \\
2. Cohort & -.03 & - & & & & & & \\
3. Employment & .04 & $.17^{b}$ & - & & & & & \\
4. Age & $.50^{b}$ & $.09^{b}$ & -.01 & - & & & & \\
5. Education & -.03 & $.24^{b}$ & $.15^{b}$ & -.04 & - & & & \\
6. Marital status & -.07 & -.03 & $-.35^{b}$ & $-.12^{b}$ & .02 & - & & \\
7. Anxiety & .02 & $.08^{b}$ & $-.08^{b}$ & .06 & $-.10^{b}$ & -.06 & - & \\
8. Immobilization & -.06 & .05 & $-.10^{b}$ & -.06 & $-.09^{b}$ & -.01 & $.56^{b}$ & - \\
9. Health & -.02 & -.02 & $.18^{b}$ & $-.14^{b}$ & .18 & .01 & $-.51^{b}$ & $-.54^{b}$ \\
\hline
\end{tabular}

${ }^{a} N=684$.

${ }^{b} p<.05$.

The relationship in which we were primarily interested was the interaction between cohort membership and empty-nest status. These two factors do significantly interact for immobilization (see Fig. 2). It was expected that empty-nest Cohort II women would have the lowest well-being of all four groups, a prediction supported by the data. However, what was not anticipated was the very high level of well-being for empty-nest women of Cohort I. These results suggest that, compared to non-empty-nest women, whose well-being is equal in the two cohorts, the empty-nest stage is a positive experience for Cohort I women and a negative experience for women in Cohort II.

We also hypothesized an employment-empty-nest interaction, but empty-nest homemakers do not significantly differ in well-being from the empty-nest employed or non-empty-nest women.

Table III. ANCOVA for Well-Being by Empty Nest, Cohort, and Employment (Controlling for Age, Education, and Marital Status) ${ }^{a}$

\begin{tabular}{|c|c|c|c|c|c|c|}
\hline & \multicolumn{2}{|c|}{ Anxiety } & \multicolumn{2}{|c|}{$\begin{array}{c}\text { Immobiliza- } \\
\text { tion }\end{array}$} & \multicolumn{2}{|c|}{ Health } \\
\hline & $d f$ & $F$ & $d f$ & $F$ & $d f$ & $F$ \\
\hline Empty nest & 1 & .00 & 1 & .23 & 1 & .95 \\
\hline Cohort & 1 & $6.08^{c}$ & 1 & $4.27^{\mathrm{c}}$ & 1 & 1.19 \\
\hline Employment & 1 & $6.80^{c}$ & 1 & $9.51^{\mathrm{c}}$ & 1 & $19.28^{c}$ \\
\hline Employment $\times$ Cohort & 1 & .44 & 1 & .35 & 1 & .19 \\
\hline Employment $\times$ Nest & 1 & .75 & 1 & .02 & 1 & 1.37 \\
\hline Cohort $\times$ Nest & 1 & .01 & 1 & $4.54^{c}$ & 1 & .17 \\
\hline Employment $\times$ Cohort $\times$ Nest & 1 & .71 & 1 & $2.48^{b}$ & 1 & .01 \\
\hline Regression & 3 & & 3 & & 3 & \\
\hline Error & 675 & & 674 & & 675 & \\
\hline
\end{tabular}


Table IV. Mean Levels of Well-Being by Empty-Nest, Cohort, and Employment Status (Adjusted for Age, Education, and Marital Status)

\begin{tabular}{|c|c|c|c|c|}
\hline & \multicolumn{2}{|c|}{$\begin{array}{c}\text { Cohort I } \\
\text { (born 1898-1917) } \\
\text { Empty nest }\end{array}$} & \multicolumn{2}{|c|}{$\begin{array}{c}\text { Cohort II } \\
\text { (born 1917-1936) } \\
\text { Empty nest }\end{array}$} \\
\hline & Employed & Homemaker & Employed & Homemaker \\
\hline Anxiety & 11.40 & 13.28 & 12.32 & 13.75 \\
\hline Immobilization & 10.30 & 11.87 & 12.54 & 12.68 \\
\hline Health & 23.33 & 22.31 & 22.37 & 22.00 \\
\hline \multirow[t]{3}{*}{$N$} & 59 & 73 & 57 & 46 \\
\hline & \multicolumn{2}{|c|}{ Not empty nest } & \multicolumn{2}{|c|}{ Not empty nest } \\
\hline & Employed & Homemaker & Employed & Homernaker \\
\hline Anxiety & 12.34 & 13.37 & 12.78 & 13.81 \\
\hline Immobilization & 11.53 & 12.15 & 11.63 & 12.64 \\
\hline Health & 22.92 & 22.51 & 22.39 & 21.99 \\
\hline$N$ & 85 & 154 & 117 & 91 \\
\hline
\end{tabular}

A three-way interaction in which Cohort II empty-nest homemakers were expected to have particularly low well-being, compared to women with other combinations of these factors, is not statistically significant. There is a trend at marginal significance, however, for immobilization. This interesting pattern (see Fig. 3) suggests that in Cohort I, empty-nest women have higher well-being (lower immobilization scores) than non-empty nest women, but particularly if employed (employment has little effect among non-emptynest women of this cohort). In contrast, in Cohort II, non-empty-nest women have higher well-being, especially if employed, but well-being does not differ by employment status for the empty-nest women (who have overall

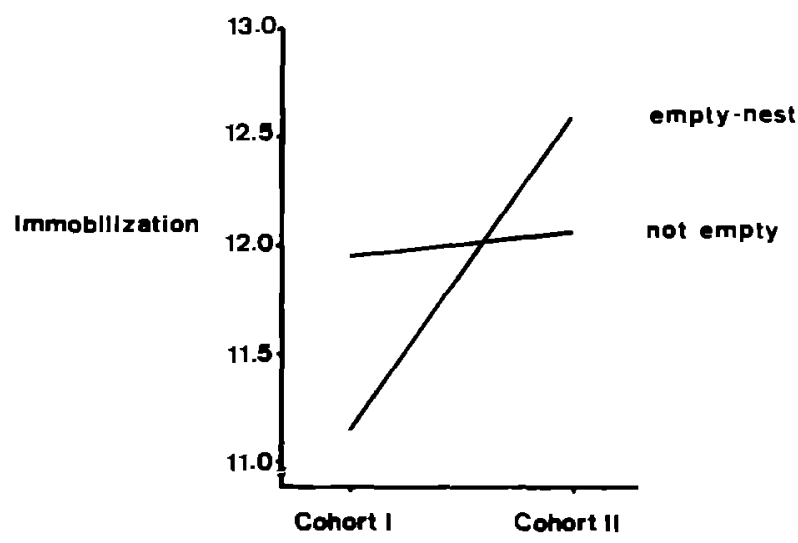

Fig. 2. Mean levels of immobilization by cohort and empty-nest status (adjusted for age, education, and marital status). 


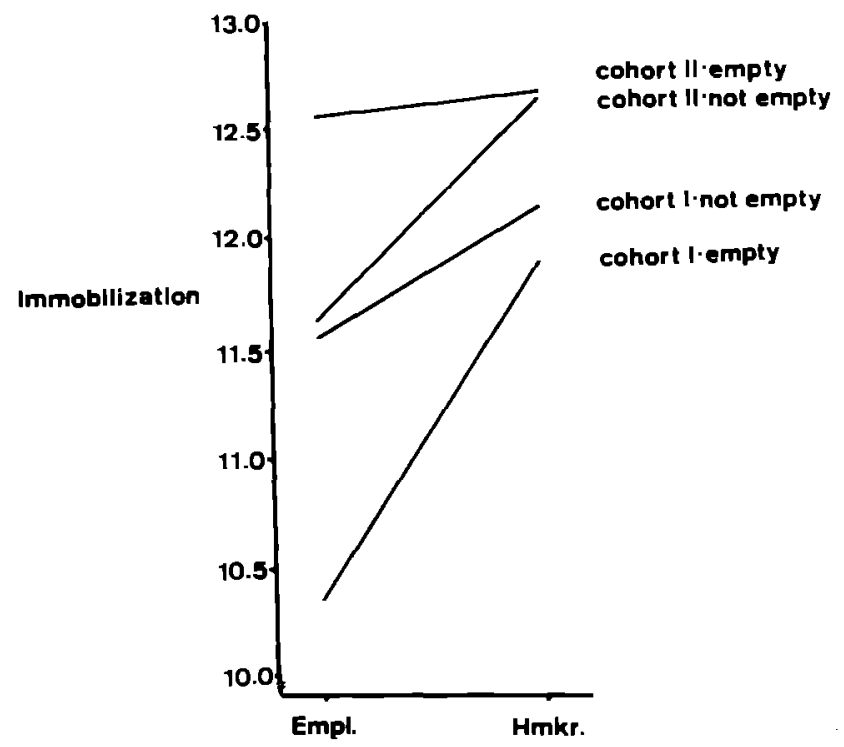

Fig. 3. Mean levels of immobilization by cohort, empty-nest and employment status (adjusted for age, education, and marital status).

higher immobilization in this cohort). The hypothesis that Cohort II emptynest homemakers would have the most distress of all groups was not supported; although they did have the highest adjusted mean levels of immobilization, the planned contrast was only marginally significant $[F(1,2.42), p$ $=.12]$.

Four subsidiary hypotheses were also tested. First, no evidence is found for a main effect of empty-nest status. Midlife women in the empty-nest stage do not have significantly different well-being than women with children at home.

The main effect of cohort shows, as expected, that midlife women in Cohort II have lower well-being than women in Cohort I (on two of the three dependent variables; there was no cohort difference in health). These cohort differences therefore parallel those reported by Veroff et al. (1981) for the entire adult sample.

The anticipated main effect of employment is also significant. Employed midlife women have higher well-being than full-time homemakers on all three dependent variables.

Finally, employment status does not interact with cohort membership. Our hypothesis was that women with a "match" between work status and the ideology about women's roles at time of measurement would have greater well-being than women with a "mismatch," but as suggested by the main 
effects, midlife women benefit from employment regardless of their cohort membership and women of the earlier cohort have higher well-being regardless of their employment status.

\section{DISCUSSION}

Past research and theory has suggested that women's well-being at midlife may be influenced by empty-nest status, but that any association may depend on cohort membership and employment status. The results of this study show that cohort and employment have important effects on well-being by themselves, whereas empty-nest status has no main effect but interacts with these two factors, especially cohort membership, in its association with well-being.

As expected, there was an overall effect of cohort membership on women's well-being at midlife. Women from Cohort I, surveyed in 1957, had significantly higher well-being than women from Cohort II. Veroff et al. (1981) found the same change in well-being from 1957 to 1976 in the full sample of adults over 21 . One explanation is that the American culture as a whole experienced a change in psychological orientation across the 20 years between the two surveys. Because of the greater societal emphasis on introspection and well-being, respondents in Cohort II might have been both more aware of and more willing to report signs of psychological distress in their lives. Interestingly, this cohort difference appeared on the two more psychological indices of well-being (anxiety and immobilization), but there was no difference in reported physical health symptoms.

One of the major developmental hypotheses with implications for wellbeing at midlife is the notion of the crossover effect. For women of the generations included in this study, a shift was often likely to have occurred in which achievement needs, unattended during the nurturant years of young adulthood, became dominant by midlife and the ending of child-rearing responsibilities. Increasing evidence has shown that women involved in achievement-oriented activities at midlife, in particular, paid employment, have higher well-being than full-time homemakers. The results of this study add to that pool of evidence: employed midlife women had lower anxiety and immobilization and better health than full-time homemakers. Particularly interesting is that the positive relationship between paid employment and well-being did not differ between the two cohorts: women employed in 1957 , in the midst of the feminine mystique, benefited from this role as much as women employed during the women's liberation period of 1976.

Previous examinations of the empty-nest syndrome have been inconsistent in their results. Occasional negative consequences were reportedand occasional positive ones - but in general there appeared little convinc- 
ing evidence that the empty nest has much effect on women's well-being at midlife. Indeed, we found no main effect of empty-nest status on well-being in this study. Borland (1982), however, proposed that if the empty-nest syndrome ever occurs, it is most likely to be found among the unique cohort (corresponding to our Cohort II) of women whose young adulthood coincided with the motherhood-oriented period following World War II; Bernard (1975) expected the syndrome in an earlier cohort (similar to our Cohort I). In this study, the significant interaction found between empty nest and cohort substantiated Borland's hypothesis. Non-empty-nest women (mothers with children still at home) in the two cohorts did not differ in well-being. Empty-nest women in Cohort II, young adults during the feminine mystique, showed the highest degree of immobilization at midlife. In contrast, Cohort I women, whose young adulthoods coincided with World War II, experienced the empty-nest stage as a positive phenomenon; they had the lowest immobilization of any group of midlife women in the study.

Contrary to expectations, involvement in paid employment did nothing to ameliorate the negative experience of the empty nest among Cohort II women. Immobilization, however, was marginally lower among the nonempty-nest women of this cohort if employed (and was uniformly high among the empty-nest women). In Cohort I, on the other hand, employment made the most difference among empty-nest women (immobilization was lower for the employed) and made somewhat less difference among the non-emptynest women.

The interacting effect of empty nest and cohort on well-being has several implications. For example, it may be possible to explain the somewhat contradictory results of previous research on the empty-nest syndrome by determining the historical cohort of the women included in the samples. Perhaps samples showing a positive experience of the empty nest overlapped with our Cohort I, whereas women with distressed empty-nest experiences were historical peers of Cohort II women.

We have assumed that one of the reasons our two cohorts differed in their experience of the empty nest was the difference in how heavily involvement in the maternal role was emphasized during young adulthood. Of course, within any one cohort of women there is likely to be a wide range of individual exposure and adherence to this cultural ideology. As a further extension of the present study, women from traditional vs. nontraditional family backgrounds within the same cohort could be compared in their experience of the empty nest. We would expect, for example, that even within our cohort of women who matured during the feminine mystique, those who more completely adopted its ideology would experience more distress during the empty nest than women who deviated from this ideological norm.

In addition, it would be informative to replicate this study in different samples of women and with outcomes measuring different facets of well- 
being. Borland (1982) proposed that not only is the empty-nest syndrome unique to a particular historical cohort of women, it may be unique to white women with that cohort. She argued that the empty-nest syndrome may not occur, for example, among women who are black or Mexican-American. In addition, we were limited in our selection of well-being constructs to those that were assessed in both the 1957 and 1976 surveys. The validity of our results could be extended by replication using other outcome measures, such as depression, self-esteem, and so on.

A final prediction that could be made based on the results of this study is what the experience of the empty nest will be like for the women of Cohort III - women whose young adulthood coincided with the feminist movement of the 1960s and 1970s, and who are now in the midst of midlife. The young adulthood ideology about women's roles for this cohort had more in common with that of Cohort I - their grandmothers - than of Cohort II. But Cohort III women are unlikely to experience an ideological backlash against women's employment during their midlife experience, as did the women of Cohort I. In addition, more of the current cohort of midlife women have experienced uninterrupted labor force participation, in contrast to the $\mathrm{M}$ shaped pattern of earlier cohorts (Shank, 1988), meaning potentially better job conditions and higher pay for these women. We would therefore expect that the empty-nest experience for the upcoming cohort of midlife women will be as positive an experience as it was for midlife women in 1957 - if not more so.

\section{REFERENCES}

Anderson, K. Wartime women: Sex roles, family relations, and the status of women during World War II. Westport, CT: Greenwood Press, 1981.

Axelson, $\mathrm{L}$. J. Personal adjustment in the post parental period. Marriage and Family Living, $1960,22,66-68$.

Bart, P. B. Depression in middle-aged women. In V. Gornick \& B. K. Moran (Eds.), Woman in sexist society. New York: The New American Library, 1971.

Baruch, G. K., \& Barnett, R. Role quality, multiple role involvement, and psychological wellbeing in midlife women. Journal of Personality and Social Psychology, 1986, 51, 578-585.

Bernard, J. Women, wives, mothers: Values and options. Chicago: Aldine, 1975.

Borland, D. C. A cohort analysis approach to the empty-nest syndrome among three ethnic groups of women: A theoretical position. Journal of Marriage and the Family, 1982, $44,117-129$.

Campbell, A. The American way of mating: Marriage yes, children only maybe. Psychology Today, 1975, 8, 37-43.

Cantril, H. Public opinion, 1935-1946. Princeton, NJ: Princeton University Press, 1951

Chafe, W. H. The American woman: Her changing social, economic and political roles, 1920-1970. New York: Oxford University Press, 1972

Coleman, L. M., \& Antonucci, T. C. Impact of work on women at midlife. Developmental Psychology, 1983, 19, 290-294

Curlee, J. Alcoholism and the empty-nest. Bulletin of the Menninger Clinic, 1969, 33, 165-171. 
Deckard, B. The women's movement: Political, socioeconomic, and psychological issues. New York: Harper \& Row, 1975.

Deutscher, I. The quality of postparental life: Definitions of the sicuation. Journal of Marriage and the Family, 1964, 26, 52-59.

Faver, C. A. Women in transition: Career, family and life satisfaction in three cohorts. Toronto: Praeger, 1984

Fox, M. F., \& Hesse-Biber, S. Women at work. Palo Alto, CA: Mayfield Publishing Co., 1984.

Friedan, B. The feminine mystique. New York: Norton, 1963.

Giele, J. Z. Women's work and family roles. In J. Z. Giele (Ed.), Women in the middle years. Toronto: Wiley, 1982.

Glazer, N. Housework: A review essay. In N. Glazer \& H. Waehrer (Eds.), Woman in a manmade world. Chicago: Rand McNally, 1977.

Gove, W. R., Grimm, J. W., Motz, S. C., \& Thompson, J. D. The family life cycle: Internal dynamics and social consequences. Sociology and Social Research, 1973, 57, 182-195.

Gurin, G., Veroff, J., \& Feld, S. Americans view their mental health. New York: Basic Books, 1960 .

Guttman, D. L. Parenthood: A key to the comparative study of the life cycle? In N. Datan \& L. Ginsberg (Eds.), Life-span developmental psychology: Normative life crises. New York: Academic Press, 1975.

Lowenthal, M. R., \& Chiriboga, D. Transition to the empty-nest: Crisis, challenge, or relief? Archives of General Psychiatry, 1972, 26, 8-14.

MacMillan, A. M. The health opinion survey: Technique for estimating prevalence of psychoneurotic and related types of disorder in communities. Psychological Reports, 1957. $3,325-329$.

National Manpower Council. Womenpower. New York, 1957.

Neugarten, B. L. The awareness of middle age. In B. L. Neugarten (Ed.), Middle age and aging. Chicago: University of Chicago Press, 1968.

Oakley, A. Woman's work. New York: Pantheon Books, 1974

Oppenheimer, V. K. The female labor force in the United States. Westport, CT: Greenwood Press, 1970.

Oppenheimer, V. K. The life-cycle squeeze: The interaction of men's occupational and family life cycles. Demography, 1974, 11, 227-245.

Phillips, B. S. A role theory approach to adjustment in old age. American Sociological Review, $1957,22,212-217$.

Powell, V. The empty nest, employment, and psychiatric symptoms in college-educated women. Psychology of Women Quarterly, 1977, 2, 35-43.

Rollins, R. C., \& Feldman, H. Marital satisfaction over the family life cycle. Journal of Marriage and the Family, 1970, 32, 20-28.

Rossi, A. Life-span theories and women's lives. Signs, 1980, 6, 4-32.

Rubin, L. Women of a certain age. New York: Harper \& Row, 1979

Scharf, L. To work and to wed: Female employment, Jeminism, and the Great Depression. Westport, CT: Greenwood Press, 1980.

Shank, S. E. Women and the labor market: The link grows stronger. Monthly Labor Review, $1988,111,3-8$.

Srole, L., Langner, T. S., Michael, S. T., Opler, M. K., \& Rennie, T. A. C. Mental health in the metropolis: The Midtown Study. New York: McGraw-Hill, 1962.

Trey, J. E. Women in the war economy - World War Il. Review of Radical Political Economics, 1972, 18, 287-294.

U.S. Department of Labor, Bureau of Labor Statistics. 1979. Employment and earnings. Washington, DC: U.S. Department of Labor, Bureau of Labor Statistics.

Verbrugge, L. M., \& Madans, J. H. Women's roles and health. American Demographics, 1985, 7, 36-39.

Veroff, J., Douvan, E., \& Kulka, R. The inner American. New York: Basic Books, 1981.

Williams, J. H. Psychology of women: Behavior in a biosocial context. New York: Norton, 1977. 